\title{
Modification of the thermogenic effect of acutely inhaled salbutamol by chronic inhalation in normal subjects
}

\author{
S R Wilson, P Amoroso, J Moxham, J Ponte
}

\begin{abstract}
Background-Acute inhalation of clinical doses of salbutamol in normal volunteers increases resting metabolic rate by up to $20 \%$ above control values. This study was designed to see if chronic treatment with salbutamol causes a sustained increase in metabolic rate and whether it modifies the acute thermogenic response to the drug.
\end{abstract}

Methods-The effects of chronic inhaled salbutamol on resting oxygen consumption $\left(\mathrm{Vo}_{2}\right)$ and carbon dioxide output $\left(\mathrm{VCO}_{2}\right)$ were studied in seven normal subjects (age 20-47 years, weight 52-105 kg, five men). An open canopy method of indirect calorimetry was used to measure $\mathrm{Vo}_{2}, \mathbf{V C O}_{2}$, and respiratory quotient (RQ). Subjects inhaled two pufís of salbutamol or placebo four times a day in a double blind manner. Measurements of resting $\mathrm{VO}_{2}$ and $\mathrm{VCO}_{2}$ after 10 days of salbutamol were compared with the values after 10 days of placebo and with those taken at the start of the study. At the end of each treatment period subjects inhaled eight puffs ( $800 \mu \mathrm{g})$ of salbutamo and the acute effects on $\mathbf{V O}_{2}, \mathbf{V C O}_{2}$ and RQ were monitored for one hour.

Results-Resting $\mathbf{V O}_{2}, \hat{V}_{\mathrm{CO}_{2}}$, and $\mathbf{R Q}$ were not significantly different at the end of the salbutamol and placebo periods but the acute response to eight puffs of salbutamol was abolished by regular inhalation. The mean $\mathrm{Vo}_{2}$ integrated over one hour after $800 \mu \mathrm{g}$ salbutamol given acutely was different $(241.3$ and $210.7 \mathrm{ml} / \mathrm{kg} / \mathrm{h}$ in the placebo and salbutamol groups respectively). Differences were not significant between placebo and salbutamol groups for changes in $\mathbf{V C O}_{2}$, heart rate, blood pressure, and $R Q$ after acute inhalation.

Conclusion-Regular treatment with inhaled salbutamol (800 $\mu \mathrm{g} / \mathrm{day})$ does not cause a sustained increase in resting metabolic rate but prevents the increase in $\mathrm{VO}_{2}$ that occurs after acute inhalations in normal subjects.

(Thorax 1993;48:886-889)

Sympathomimetic drugs can cause an increase in resting metabolic rate when given intravenously. ${ }^{2}$ In an accompanying paper we report increases in whole body oxygen consumption $\left(\mathrm{VO}_{2}\right)$ and carbon dioxide production $\left(\mathrm{VCO}_{2}\right)$ after acute inhalation of salbutamol, ${ }^{3}$ but the effects of chronic administration of salbutamol on $\dot{\mathrm{VO}}_{2}$ and $\dot{\mathrm{VCO}}_{2}$ have not to our knowledge been studied. It has been reported that two weeks of regular oral terbutaline induces a sustained (7.8\%) increase in $\dot{\mathrm{VO}}_{2}$ and that the thermogenic effects of intravenous isoprenaline are reduced during treatment with terbutaline. ${ }^{4}$

We report the effects of 13 days of clinical doses of inhaled salbutamol on resting metabolic rate and the effect of this long term treatment on the acute thermogenic response to the drug.

\section{Methods}

Seven healthy non-smoking volunteers (five men) aged 20-47 years and weighing 52-105 $\mathrm{kg}$ were studied after fasting and abstaining from caffeine for at least six hours. Approval of the local ethics committee and the subjects' informed consent were obtained. Measurements of $\mathrm{VO}_{2}$ and $\mathrm{VCO}_{2}$ were made by an open canopy technique with a mass spectrometer (Airspec Ltd) linked to a microcomputer, as described in the accompanying paper. ${ }^{3}$ The airflow through the canopy ranged between 85 and $110 \mathrm{l} / \mathrm{min}$. Subjects were studied after reclining on a comfortable couch and listening to quiet music for at least 30 minutes. All seven subjects had been volunteers in a previous study of the acute metabolic effects of inhaled salbutamol during which at least eight resting measurements of $\dot{\mathrm{VO}}_{2}$ and $\dot{\mathrm{VCO}}_{2}$ were made in each subject. ${ }^{3}$ Thus the individual variability was known and all subjects were accustomed to the pro-

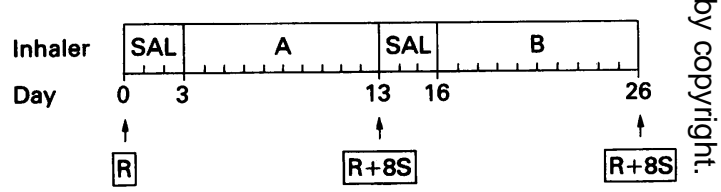

Figure 1 Experimental design for the inhalation of two puffs of salbutamol (SAL), inhaler $A$, or inhaler $B$ every six hours for 26 days. Resting $\dot{V} \mathrm{O}_{2}$ and $\dot{\mathrm{V}} \mathrm{CO}_{2}$ measure ments were taken at points [R]. Measurements of the acute response to eight puffs of salbutamol were taken at points [8S]. 
Table 1 Mean (SE) values of resting $\dot{V}_{2}, \dot{V} \mathrm{CO}_{2}$, and $R Q$ in seven subjects.

\begin{tabular}{llll}
\hline & Day 0 & $\begin{array}{l}\text { Placebo } \\
\text { (10 days) }\end{array}$ & $\begin{array}{l}\text { Salbutamol } \\
\text { (13 days) }\end{array}$ \\
\hline$\dot{\mathrm{V}}_{2}(\mathrm{ml} / \mathrm{min} / \mathrm{kg})$ & $3 \cdot 22(0 \cdot 08)$ & $3.34(0 \cdot 15)$ & $3 \cdot 50(0 \cdot 09)$ \\
$\dot{\mathrm{V}}_{2}(\mathrm{ml} / \mathrm{min} / \mathrm{kg})$ & $2 \cdot 68(0 \cdot 08)$ & $2 \cdot 77(0 \cdot 18)$ & $2 \cdot 88(0 \cdot 13)$ \\
$\mathrm{RQ}$ & $0 \cdot 83(0.01)$ & $0 \cdot 83(0.01)$ & $0 \cdot 82(0.01)$ \\
\hline
\end{tabular}

For experimental details see text and fig 1; there were no significant differences between day 0 and placebo, between day 0 and salbutamol, or between placebo and salbutamol.

cedure. An electrocardiogram (Datascope) and blood pressure (Accutorr) were recorded every five minutes during all the experiments. Barometric pressure, and temperature and humidity of the room and at the outlet of the canopy were also recorded. All experiments were performed within a period of 11 weeks and the maximum variation in room temperature and relative humidity for any subject was $5 \cdot 2^{\circ} \mathrm{C}$ and $16 \%$. The high canopy flows used avoided any sense of stuffiness or rebreathing, yet allowed accurate measurements to be made. Temperature and humidity at the outlet of the chamber during measurements increased above room values by a maximum of only $2^{\circ} \mathrm{C}$ and $4 \%$. Corrections for temperature and humidity in the measured gas volumes were not necessary because they were well below the resolution of the method (maximal correction $8 \mathrm{ml} / \mathrm{min}$ for both $\mathrm{VO}_{2}$ and $\mathrm{VCO}_{2}$ ).

Subjects took two puffs every six hours from one of a series of three inhalers labelled salbutamol, A, or B for 26 days in total. The coded inhalers (Allen and Hanburys Ltd) contained salbutamol (100 $\mu \mathrm{g} / \mathrm{puff})$ or placebo and the codes were revealed only at the end of the study. Subjects started by inhaling known salbutamol for three days, followed by 10 days of inhaler $A$, then another three days of known salbutamol and finally 10 days of inhaler B (fig 1). Inhalation of known salbutamol for three days made it difficult for the subject to determine what was contained in the subsequent coded inhalers, a

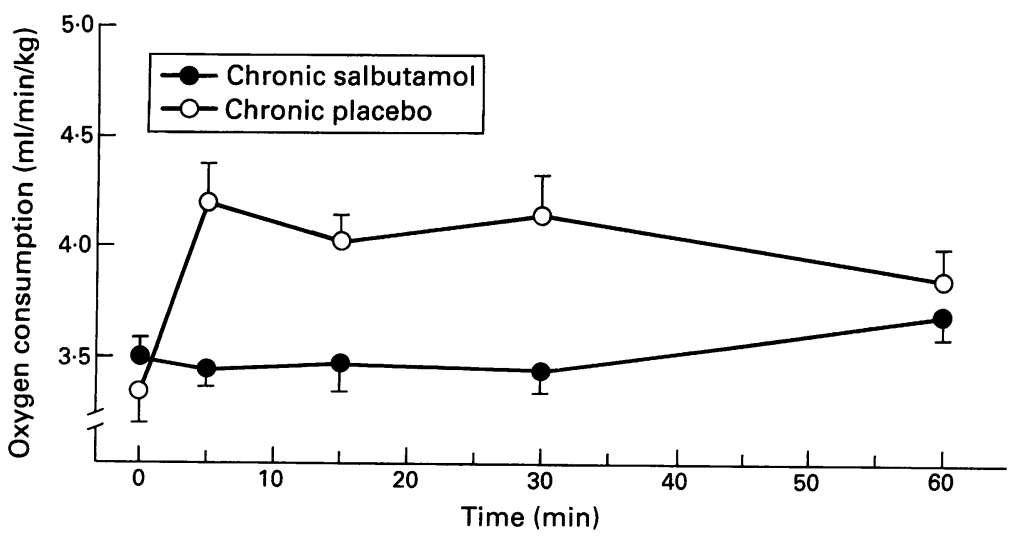

Figure 2 Mean values of $\dot{\mathrm{V}} \mathrm{O}_{2}$ after inhalation of $800 \mu \mathrm{g}$ salbutamol in seven subjects under two test conditions: after 13 days of regular salbutamol treatment and after 10 days of placebo. Bars = SE technique successfully used in previous studies. $^{5}$

Measurements of resting $\dot{\mathrm{VO}}_{2}$ and $\dot{\mathrm{VCO}}_{2}$ were taken first thing in the morning on the first day of the study before any inhalations and on days 13 and 26 (fig 1), when subjects had omitted the morning regular dose of inhaler; these measurements were thus made 8-10 hours after the last regular inhalation. The resting measurements (expressed in $\mathrm{ml} / \mathrm{min} / \mathrm{kg}$ ) obtained at the end of 13 days of salbutamol were compared with those after 10 days of placebo and both these sets of values were compared with values obtained on day 0 .

The acute thermogenic effect of eight puffs $(7 \cdot 6-15 \cdot 4 \mu \mathrm{g} / \mathrm{kg}$ ) of salbutamol was also measured at the end of each of the periods of long term salbutamol and placebo. This dose of salbutamol was used because it had caused a clear thermogenic effect in all subjects in a previous study. ${ }^{3}$ The resting measurements of $\dot{\mathrm{VO}}_{2}$ and $\dot{\mathrm{VCO}}_{2}$ taken just before acute inhalations of salbutamol are designated in this study as baseline measurements. After obtaining these baseline values, the subject inhaled eight puffs of salbutamol via a spacer device. Records of $\dot{\mathrm{VO}}_{2}$ and $\mathrm{VCO}_{2}$ were made for 60 minutes thereafter and the results were integrated to obtain the area under the curve. These acute responses to eight puffs of salbutamol after 13 days of regular treatment were then compared with the acute responses after 10 days of placebo. A paired $t$ test was used for all comparisons.

Subjects were asked about side effects, such as tremor, changes in appetite, and sleep pattern, associated with the regular inhalations.

\section{Results}

There were no significant differences between the resting baseline values of $\dot{V O}_{2}, \dot{V} \mathrm{CO}_{2}, R Q$, heart rate and mean blood pressure at the end of 13 days of salbutamol compared with 10 days of placebo and there were no significant differences between day 0 and days 13 or 26 (table 1).

An acute thermogenic response, measured as a rise in $\dot{\mathrm{VO}}_{2}$ after eight puffs of salbutamol, was seen at the end of the placebo period but not at the end of the salbutamol period (fig 2). The mean $\mathrm{Vo}_{2}$ during one hour after eight puffs of salbutamol was $14.5 \%$ higher in the placebo group than in the chronic salbutamol group. The patterns of changes in $\mathrm{VCO}_{2}$ and heart rate in response to eight puffs of salbutamol (figs 3 and 4) were similar but the differences were not significant between the two groups (table 2). There were no differences in measurements of $R Q$ and blood pressure between the placebo and salbutamol groups after eight puffs of salbutamol.

None of the subjects could distinguish between inhalers A and B; they were thus not aware of when they were taking the active drug. No side effects due to the chronic inhalation of salbutamol were reported by any of the subjects. 


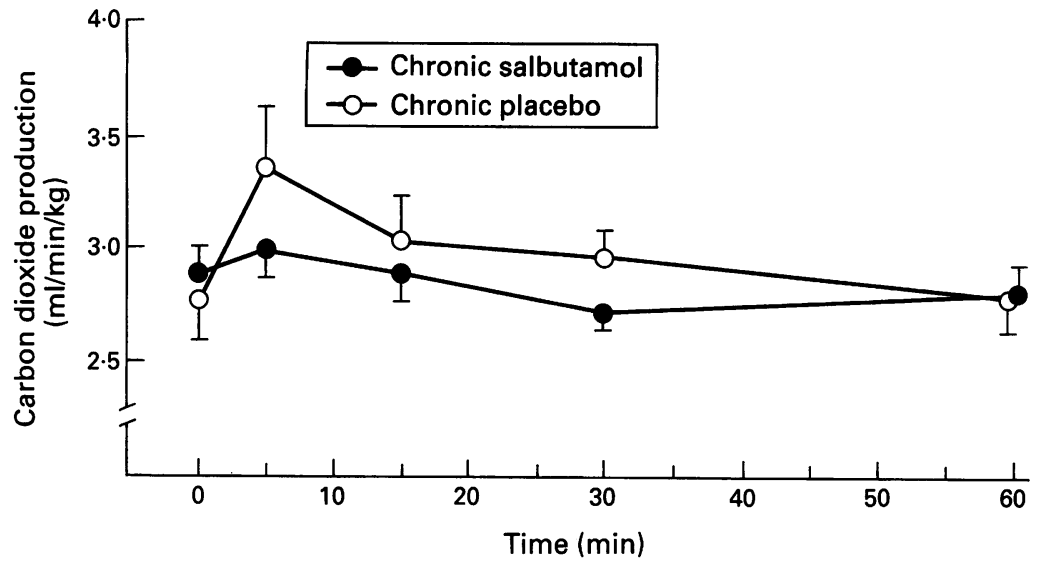

Figure 3 Mean values of $\mathrm{VCO}_{2}$ after inhalation of $800 \mu \mathrm{g}$ salbutamol. Test conditions as in fig 2.

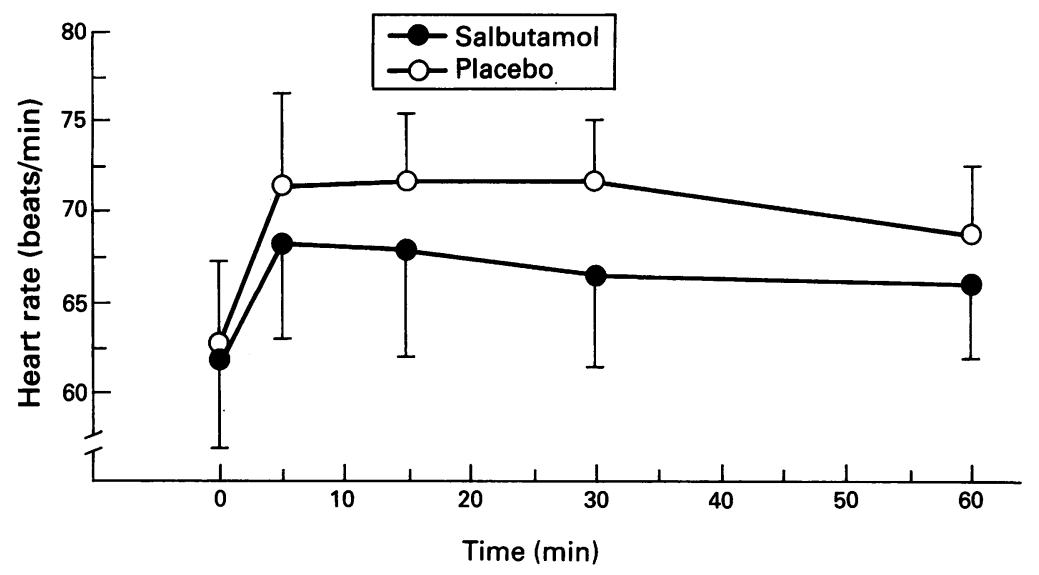

Figure 4 Mean values of heart rate after inhalation of $800 \mu \mathrm{g}$ salbutamol. Test conditions as in fig 2. surements on the first day $(3 \cdot 7 \%$ and $3 \cdot 4 \%$ respectively). We were careful to always take the resting measurements of $\mathrm{VO}_{2}$ and $\mathrm{VCO}_{2}$ at the lowest plasma concentration of salbutamol (more than eight hours after the last regular inhalation), to determine only the chronic rather than the acute effects of the drug.

The most interesting finding was that regular salbutamol for 13 days completely blunted the acute thermogenic response to a single high $(800 \mu \mathrm{g})$ dose of the drug. We believe that this finding is of practical importance for patients on regular salbutamol treatment. Our results agree fully with previous reports of the attenuation of the acute bronchodilator response to salbutamol after chronic stimulation in normal subjects ${ }^{78}$ and partly with reports of attenuation of the acute thermogenic and cardiovascular responses to other $\beta$ agonists. ${ }^{49}$ It was surprising to find that the effects on $\mathrm{VCO}_{2}$ and heart rate of the acute (eight puffs) salbutamol treatment were not 은 different between the chronic placebo and $\vec{c}$ salbutamol groups in view of the clear effects of eight puffs of salbutamol compared with placebo found in a preceding study. ${ }^{3}$ This lack of significance may have resulted either from the smaller number of subjects in this study (seven compared with 10 in the previous study) or from a dissociation between the down regulation of the thermogenic and cardiac effects of the drug. Regarding the bronchodilator response, available publications are unclear; one report suggests that chronic treatment with salbutamol does not affect the $\overline{\vec{\beta}}$ acute bronchodilator response in asthmatic $\frac{9}{3}$ patients. ${ }^{9}$ Another report suggests that the thermogenic response to ephedrine may even be enhanced during long term treatment with the drug in obese women. ${ }^{10}$

In conclusion, the thermogenic response to acute salbutamol in normal subjects is attenuated by prolonged use of the drug. It is unlikely that the increase in resting metabolic rate reported in patients with chronic airflow limitation ${ }^{1}$ is caused by long term treatment with $\beta$ agonists. Further studies are needed on the effects of methyl xanthines on metabolic rate before attributing the higher resting $\dot{\mathrm{VO}}_{2}$ and $\dot{\mathrm{VCO}}_{2}$ in these patients exclusively to the increased work of breathing. . $7.5 \%$ higher than the values recorded on the first day (table 1), these differences were not significant. This may be partly due to a placebo effect as suggested by the (non-significant) increase in mean resting $\dot{\mathrm{VO}}_{2}$ and $\dot{\mathrm{VCO}}_{2}$ after the placebo period when compared with mea-

Table 2 Mean (SE) values for $\dot{\mathrm{V}}_{2}$ and $\dot{\mathrm{V}} \mathrm{CO}_{2}$ integrated over one hour and heart rate averaged over one hour, for seven subjects, after inhalation of $800 \mu \mathrm{g}$ salbutamol in two experimental conditions: after 13 days of regular treatment with salbutamol and after 10 days of regular placebo

\begin{tabular}{llll}
\hline & $\begin{array}{l}\dot{\dot{V O}_{2}} \\
(\mathrm{ml} / \mathrm{kg} / \mathrm{h})\end{array}$ & $\begin{array}{l}\dot{\mathrm{V}} \mathrm{CO}_{2} \\
(\mathrm{ml} / \mathrm{kg} / \mathrm{h})\end{array}$ & $\begin{array}{l}\text { Heart rate } \\
\text { (beats } / \mathrm{min})\end{array}$ \\
\hline Salbutamol & $210 \cdot 7(4 \cdot 8)$ & $170 \cdot 0(6 \cdot 2)$ & $66 \cdot 0(4 \cdot 9)$ \\
Placebo & $241 \cdot 3(8 \cdot 9)$ & $178 \cdot 3(9 \cdot 1)$ & $70 \cdot 4(3 \cdot 6)$ \\
p value & $<0 \cdot 05$ & $\mathrm{NS}$ & $\mathrm{NS}$ \\
\hline
\end{tabular}

1 Fellows IW, Bennett T, MacDonald IA. The effect of $\frac{\bar{Q}}{\partial}$ adrenaline upon cardiovascular and metabolic functions in man. Clin Sci 1985;69:215-22.

S R Wilson was in receipt of a grant from the Joint Research Committee of King's College Hospital, which we gratefully of acknowledge. We also thank Dr R Ginsburg for help with developing the computer program used to collect the data and Allen and Hanburys Ltd for supplying salbutamol inhalers and spacer devices.
2 Frazer S, Green C, Underhill S, Fairhurst J, Maycock $P$ Campbell IT. Metabolic effects of dobutamine. $\mathrm{Br} \mathscr{f}$ Anaesth 1990;65:289P.

3 Amoroso P, Wilson SR, Moxham J, Ponte J. Acute effects of inhaled salbutamol on the metabolic rate of normal subjects. Thorax 1993;48:882-5. 
4 Scheidegger K, O'Connell M, Robbins DC, Danforth E. Effects of chronic beta-receptor stimulation on sympathetic nervous system activity, energy expenditure and thyroid hormones. F Clin Endocrinol Metab 1984;58: 895-903.

5 Brophy C, Mier A, Moxham J, Green M. The effect of aminophylline on respiratory and limb muscle contractility in man. Eur Respir $\mathcal{F} 1898 ; 2: 652-5$.

6 Bursztein S, Elwyn DH, Askanazi J, Kinney JM. Energy metabolism, indirect calorimetry and nutrition. Baltimore: Williams and Wilkins, 1989;173-209.

7 Holgate ST, Stubbs WA, Wood PJ, McCaughey ES, Alberti KGMM, Tattersfield AE. Airway and metabolic resistance to intravenous salbutamol: a study in normal man. Clin Sci 1980;59:155-61.

8 Harvey JE, Tattersfield AE. Airways response to salbutamol: the effect of regular salbutamol in normal, atopic and asthmatic subjects. Thorax 1982;37:280-7.

9 Conolly ME, Davies DS, Dollery CT, George CF Resistance to $\beta$-adrenoreceptor stimulants (a possible explanation for the rise in asthma deaths). $B r f$ Pharmacol 1971;43:389-402.

10 Astrup A, Lundsgaard C, Madsen J, Christensen NJ. Enhanced thermogenic responsiveness during chronic ephedrine treatment in man. Am $\mathcal{f}$ Clin Nutr 1985;42: 83-94. 